\title{
Changes in levels of prostate-specific antigen and testosterone following discontinuation of long-term hormone therapy for non-metastatic prostate cancer
}

\author{
Kunihisa Yamaguchi', Hirofumi Izaki', Masayuki Takahashi', Tomoharu Fukumori', \\ Masaaki Nishitani ${ }^{2}$, Yasushi Sutou ${ }^{3}, K_{\text {Kenzou Uema }}{ }^{4}$, Akira Kawano ${ }^{5}$, Takumi Hamao ${ }^{6}$, \\ and Hiro-omi Kanayama' \\ ${ }^{1}$ Department of Urology, Institute of Health Biosciences, the University of Tokushima Graduate School, \\ Tokushima, Japan, ${ }^{2}$ Kawashima Hospital, Tokushima, Japan, ${ }^{3}$ Tsurugi Municipality Handa Hospital, \\ Tokushima, Japan, ${ }^{4}$ Tokushima Red Cross Hospital, Tokushima, Japan, ${ }^{5}$ Sanuki Municipal Hospital, \\ Kagawa, Japan, ${ }^{6}$ Kamei Hospital, Tokushima, Japan
}

\begin{abstract}
Introduction : We evaluated changes in levels of prostate-specific antigen (PSA) and testosterone following discontinuation of long-term hormone therapy for non-metastatic prostate cancer. Patients and Methods : Treatment was discontinued in 31 patients with non-metastatic prostate cancer (clinical stage B-C) after $\geqq 5$ years of hormone therapy, during which time PSA level had been maintained less than $0.5 \mathrm{ng} / \mathrm{ml}$. PSA and testosterone levels were measured after discontinuation of therapy. PSA $>4.0 \mathrm{ng} / \mathrm{ml}$ was defined as PSA relapse in this study. Results : Mean age at discontinuation of hormone therapy was 78.7 years (range, 66-90). Mean duration of follow-up after discontinuation of therapy was 25.5 months. PSA non-relapse rate was quite high (87.1\%). 4 of the 31 patients showed PSA relapse, after 12-24 months. Testosterone level exceeded castration level $(<1.0 \mathrm{ng} / \mathrm{ml})$ in 3 patients, each of whom developed PSA relapse. Conclusions : During follow-up, the PSA relapse rate was relatively low. These results suggest that treatment may be safely discontinued in many prostate cancer patients. In addition, rate of testosterone recovery after treatment discontinuation may be associated with PSA relapse. When considered the adaptation of discontinued, or intermittent hormone therapy for aged people, these findings may be useful. J. Med. Invest. 61 : 35-40, February, 2014
\end{abstract}

Keywords : hormone therapy, discontinuation, PSA value, testosterone level, PSA relapse

\section{INTRODUCTION}

Hormone therapy for prostate cancer is not generally considered to achieve the complete cure seen with surgical treatment or radiotherapy, with

Received for publication July 31, 2013 ; accepted September 5, 2013.

Address correspondence and reprint requests to Kunihisa Yamaguchi, Department of Urology, Institute of Health Biosciences, the University of Tokushima Graduate School, 3-18 Kuramoto, Tokushima 770-8503, Japan and Fax : +81-88-6337160. tumor-depression effects supposedly disappearing following discontinuation of hormone therapy.

Hormone therapy for prostate cancer is thus positioned as a standard treatment for metastatic prostate cancer at present, but as shown in the CaPSURE database, the proportion of hormone therapy for localized prostate cancer has tended to increase rapidly in recent years (1). Particularly in Japan, hormone therapy has been used rather than surgical treatment for early-stage localized prostate cancer in many cases, unlike the situation in Europe and 
America. This difference is probably closely related to the health insurance system in Japan.

A recent study reported that discontinuation of medical treatment after long-term hormone therapy for localized prostate cancer causes no relapse of cancer (2). That report has attracted a great deal of attention. If prostate cancer can be controlled by long-term hormone therapy, subsequently enabling discontinuation of medical treatment, this finding will have great significance.

Accordingly, to confirm the effects of long-term hormone therapy for prostate cancer, a multi-center investigation was undertaken to determine whether discontinuation of medical treatment results in relapse among clinically controlled cases that have received long-term hormone therapy for non-metastatic prostate cancer.

\section{PATIENTS AND METHODS}

Between 2005 and 2010, hormone therapy was discontinued in our institutions for 31 patients with non-metastatic prostate cancer (clinical stage B-C) after receiving $\geqq 5$ years of hormone therapy with PSA levels maintained less than $0.5 \mathrm{ng} / \mathrm{ml}$. In contents of hormone therapy, luteinizing hormone-releasing hormone (LH-RH) agonist monotherapy and maximal androgen blockade (MAB) therapy were included. LH-RH agonist (Goserelin acetate $10.8 \mathrm{mg}$ or leuprorelin acetate $11.25 \mathrm{mg}$ ) was administered subcutaneously every three months. In the case of MAB therapy, flutamide ( $375 \mathrm{mg} /$ day) or bocalutamide $(80 \mathrm{mg} /$ day) was administered orally in addition to LH-RH agonist. However, patients who had also received surgery or radiotherapy were excluded. All participants in this study agreed to discontinue treatment and the study protocols were approved by the ethics review board at our hospital. PSA and testosterone levels were measured within 1 month before the discontinuation of hormone therapy. After confirming the absence of metastatic lesions on bone scintigraphy and computed tomography of the chest, abdomen and pelvis, hormone therapy was discontinued. PSA and testosterone levels were then measured every 1-3 months after discontinuation of therapy. Imaging examinations were performed as needed. For the purposes of this study, PSA relapse was defined as PSA level $>4.0 \mathrm{ng} / \mathrm{ml}$. When PSA relapse or a recurrent lesion was confirmed, hormone therapy was resumed. However, when patients wished the resumption of hormone therapy, their wishes were approved in any cases. And we treated these cases as censored data. Testosterone level $<1.0 \mathrm{ng} / \mathrm{ml}$ was defined as the castration level, so a level $\geqq 1.0 \mathrm{ng} / \mathrm{ml}$ indicated significant recovery from castration level in this study.

The primary end-point was the non-relapse period for PSA level after discontinuation of hormone therapy. The secondary end-point was the duration required to recover from castration level of testosterone after discontinuation of hormone therapy.

\section{RESULTS}

Mean PSA level for the 31 patients at the diagnosis of prostate cancer was $26.0 \mathrm{ng} / \mathrm{ml}$ (range, 2.2186.0), and clinical stage was B in 22 patients, and $\mathrm{C}$ in 9 patients. Gleason score was $\leqq 6$ in 16 patients, $3+4$ in 5 patients, $4+3$ in 3 patients, and $\geqq 8$ in 7 patients. Mean age at discontinuation of hormone therapy was 78.7 years (range, 66-90), and mean duration of hormone treatment was 64.5 months (range, 60-96). Hormone therapy comprised LH-RH agonist alone in 4 patients, MAB in 19 patients, and alteration from MAB therapy to LH-RH agonist alone in 8 patients (Table 1 ).

Overall mean duration of follow-up was 25.5

\begin{tabular}{lc} 
Table $1 \quad$ Patient and tumor characteristics $(\mathrm{n}=31)$ & \\
\hline & Value \\
Age at end of endocrine therapy (years) & 78.7 \\
Mean & $66-90$ \\
$\quad$ Range & \\
PSA value at diagnosis of prostate cancer $(\mathrm{ng} / \mathrm{ml})$ & \\
$\quad$ Mean & 26.0 \\
$\quad$ Range & $2.2-186.0$ \\
Duration of endocrine therapy (months) & \\
$\quad$ Mean & 64.5 \\
Range & $60-96$ \\
Contents of endocrine therapy (n) & \\
LH-RH agonist alone & 4 \\
MAB therapy & 19 \\
MAB $\rightarrow$ LH-RH agonist alone & 8 \\
Clinical stage (n) & \\
Stage B & 22 \\
Stage C & 9 \\
Gleason score (n) & \\
$\leqq 6$ & 16 \\
$3+4$ & 5 \\
$4+3$ & 3 \\
$\geqq 8$ & 7 \\
\hline
\end{tabular}


months (range, 14-57). Two of the 31 patients requested resumption of hormone therapy during this study. PSA relapse was identified in 4 patients (12.9\%), with non-relapse in 27 (87.1\%). Mean duration of follow-up was 18.3 months (range, 15-20) for PSA relapse cases, compared to 25.6 months (range, 13-57) for PSA non-relapse cases. No prostate cancer-specific deaths were identified during this study (non-specific death, 4 patients).

Viewing the transition of PSA levels after discontinuation of hormone therapy, the 4 patients who developed PSA relapse showed increases in the early stage after discontinuation, and PSA relapse was confirmed in all 4 patients within 12-24 months
(Figure 1). In terms of testosterone level after discontinuation of hormone therapy, recovery to above castration level was found in 3 patients from an early stage, with levels maintained below castration level during follow-up in all other cases (Figure 2). All 3 patients with testosterone recovery to above castration level developed PSA relapse.

Comparison of parameters between PSA non-relapse and relapse cases showed that median PSA level in relapse cases at the time of prostate cancer diagnosis tended to be higher $(19.5 \mathrm{ng} / \mathrm{ml}$; range, $11.1-186.0)$ than in non-relapse cases $(9.8 \mathrm{ng} / \mathrm{ml}$; range, 2.2-70.5). In addition, median age at discontinuation of hormone therapy tended to be lower in

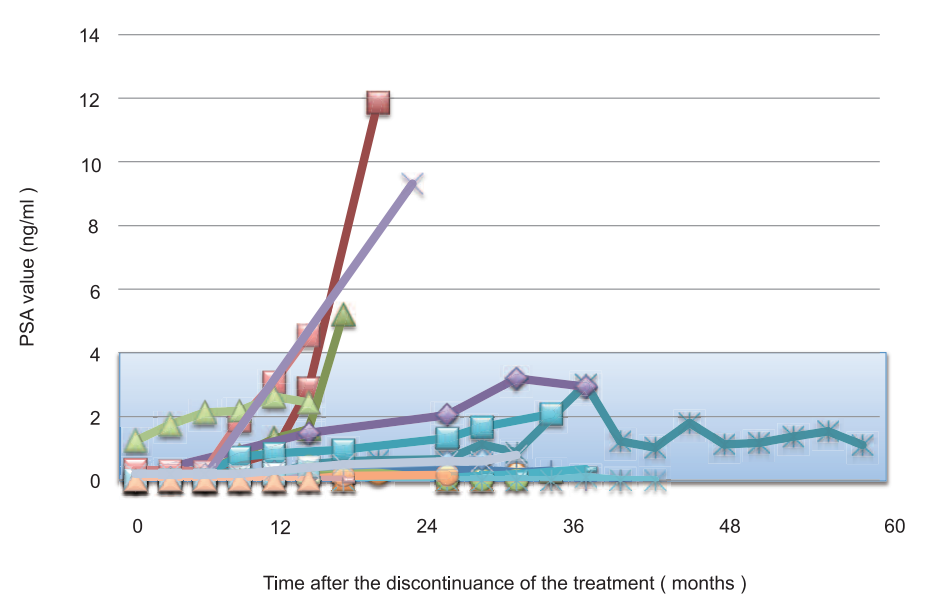

Figure 1 : Changes in PSA level after discontinuation of hormone therapy.

PSA level $>4.0 \mathrm{ng} / \mathrm{ml}$ was defined as PSA relapse in this study (outside the blue area in Figure 1). The color lines showed the change of PSA level of each cases.

Four patients experienced PSA relapse from 12 months to 24 months after discontinuation of treatment.

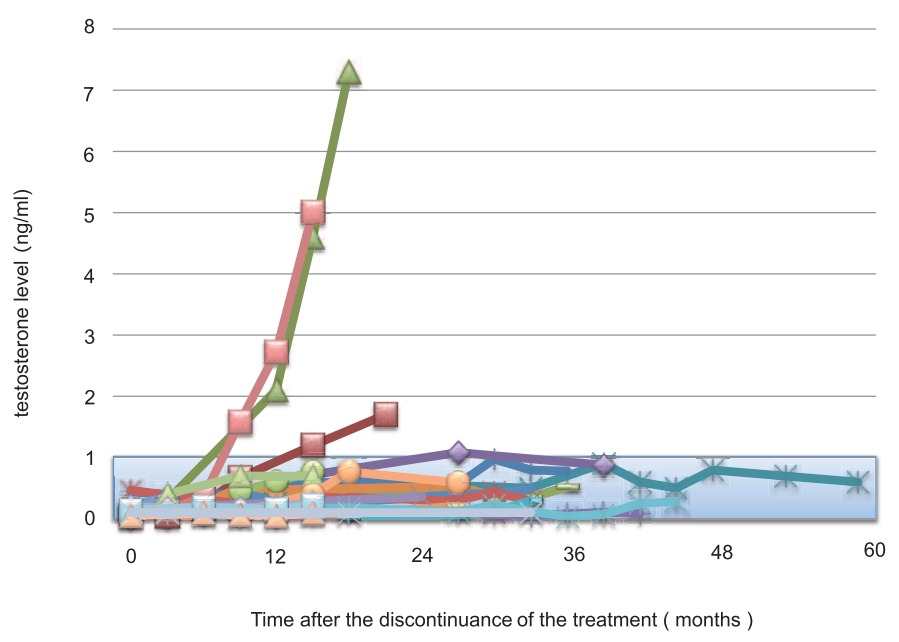

Figure 2 : Changes in testosterone level after discontinuation of hormone therapy.

Testosterone level $\geqq 1.0 \mathrm{ng} / \mathrm{ml}$ indicated significant recovery from castration level in this study (outside the blue area in Figure 2). The color lines showed the change of testosteron level of each cases.

Recovery to above castration level was found in 3 patients and all 3 patients developed PSA relapse. 
relapse cases (74 years ; range, 66-76) than in nonrelapse cases (80 years ; range, 67-90). Conversely, no specific tendencies in clinical stage or Gleason score at diagnosis were observed, and non-relapse cases included patients with stage $\mathrm{C}$ or Gleason score $4+3$ or $\geqq 8$. Also, contents of long-term hormone therapy and duration of hormone therapy showed no specific tendencies between groups. Final testosterone level and median rate of testosterone increase were $0.29 \mathrm{ng} / \mathrm{ml}$ (range, 0.10-1.27) and $0.005 \mathrm{ng} / \mathrm{ml} / \mathrm{month}$ in non-relapse cases, and $3.35 \mathrm{ng} / \mathrm{ml}$ (range, 0.36-7.29) and $0.246 \mathrm{ng} / \mathrm{ml} /$ month in relapse cases. Both the final level and rate of increase were higher in relapse cases than in nonrelapse cases (Table 2).

Table 2 Comparison between each parameter in PSA nonrelapse and relapse cases

\begin{tabular}{|c|c|c|}
\hline & $\begin{array}{l}\text { PSA non-relapse } \\
\quad(\mathrm{n}=27)\end{array}$ & $\begin{array}{l}\text { PSA relapse } \\
(\mathrm{n}=4)\end{array}$ \\
\hline \multicolumn{3}{|c|}{$\begin{array}{l}\text { PSA value at diagnosis of prostate } \\
\text { cancer }(\mathrm{ng} / \mathrm{ml})\end{array}$} \\
\hline Median & 9.8 & 19.5 \\
\hline Range & $2.2-70.5$ & $11.1-186.0$ \\
\hline \multicolumn{3}{|l|}{ Clinical stage (n) } \\
\hline Stage B & 19 & 3 \\
\hline Stage C & 8 & 1 \\
\hline \multicolumn{3}{|l|}{ Gleason score (n) } \\
\hline$\leqq 6$ & 14 & 2 \\
\hline $3+4$ & 5 & 0 \\
\hline $4+3$ & 3 & 0 \\
\hline$\geqq 8$ & 5 & 2 \\
\hline \multicolumn{3}{|l|}{ Contents of endocrine therapy (n) } \\
\hline LH-RH agonist alone & 4 & 0 \\
\hline MAB therapy & 17 & 2 \\
\hline $\mathrm{MAB} \rightarrow \mathrm{LH}-\mathrm{RH}$ agonist alone & 6 & 2 \\
\hline \multicolumn{3}{|l|}{$\begin{array}{l}\text { Duration of endocrine therapy } \\
\text { (months) }\end{array}$} \\
\hline Median & 61.0 & 68.0 \\
\hline Range & $60-62$ & $60-96$ \\
\hline \multicolumn{3}{|l|}{$\begin{array}{l}\text { Age at end of endocrine therapy } \\
\text { (years) }\end{array}$} \\
\hline Median & 80 & 74 \\
\hline Range & $67-90$ & $66-76$ \\
\hline \multicolumn{3}{|l|}{ Final testosterone level (ng/ml) } \\
\hline Median & 0.29 & 3.35 \\
\hline Range & $0.10-1.27$ & $0.36-7.29$ \\
\hline \multicolumn{3}{|l|}{$\begin{array}{l}\text { Rate of testosterone increase (ng/ } \\
\mathrm{ml} / \mathrm{month})\end{array}$} \\
\hline Median & 0.005 & 0.246 \\
\hline Range & $-0.006-0.052$ & $0.011-0.436$ \\
\hline
\end{tabular}

\section{DISCUSSION}

Hormone therapy has held a place as one of the key treatment strategies for prostate cancer since Huggins et al. reported its efficacy in 1941 (3). Hormone therapy is chosen for treatment of localized prostate cancer more often in Japan than in Europe and America. In a study of cancer-specific survival rates for prostate cancer treated using hormone therapy as the initial therapy, Akaza et al. reported good results of $91 \%$ at 5 years and $78 \%$ at 10 years (4). Similarly, Ueno et al. reported an 8-year survival rate of $89.1 \%$ (5). However, the likelihood of radical cure of prostate cancer by hormone therapy, and the subsequent clinical results at discontinuation of hormone therapy, have remained unclear until now, leaving room for argument.

Concerning the likelihood of radical cure, Labrie et al. reported in 2002 that $90 \%$ of patients with Stage $\mathrm{B}$ or $\mathrm{C}$ prostate cancer treated using hormone therapy for $>6.5$ years showed no relapse of PSA during 5 years of follow-up (1). As a theory supporting the radical cure of prostate cancer by hormone therapy, Namiki et al. stated that "In the progressive cancer stage, hormone therapy-refractory prostate cancer cells increase in 3-4 years, and as a result, hormone therapy-resistance comes to be shown. In contrast, hormone-naive monoclonal cells in the early stage may be susceptible to apoptosis from hormone therapy. Radical cure for prostate cancer may thus be quite possible" (6).

No patients in this study had metastatic prostate cancer, and all patients had PSA $<0.5 \mathrm{ng} / \mathrm{ml}$, representing stable disease status after continuing hormone therapy for $\geqq 5$ years. However, patients with high PSA at diagnosis, high Gleason score, and stage $\mathrm{C}$ disease, representing so-called high-risk patients, were included. Even so, only 4 of 31 patients showed PSA relapse after discontinuation of treatment during the mean follow-up period of 25.5 months. Furthermore, the 27 PSA non-relapse cases included 10 of the 12 high-risk patients. Likewise, in this study, the 3 patients in whom testosterone level returned to above castration level after discontinuation of hormone therapy experienced PSA relapse in the same period. Only 1 patient (stage $\mathrm{C}$; PSA, $184 \mathrm{ng} / \mathrm{ml}$ and GS $5+4$ at diagnosis) experienced PSA relapse without a recovery in testosterone level. Given these results, not the radical cure of prostate cancer by long-term hormone therapy suggested by Labrie et al., but rather the speed of recovery in blood testosterone level after long-term 
hormone therapy was the factor exerting the greatest influence on PSA relapse.

Studies of blood testosterone levels after discontinuation of hormone therapy have reported substantial variations in results. Wilke et al. reported that when treatment was discontinued after hormone therapy for $\geqq 24$ months, testosterone level exceeded castration level in $75 \%$ of patients within 6 months after treatment discontinuation (7). Conversely, Kaku et al. reported that when treatment was discontinued after hormone therapy for a mean of 30 months, testosterone level returned to above castration level within 2 years in $90 \%$ of patients (8). According to the reports of Nejat et al. and Oefelein et al., patients who have received long-term LH$\mathrm{RH}$ agonists require longer to achieve recovery of testosterone levels $(9,10)$.

In the present study, hormone therapy was continued for longer ( $\geqq 60$ months) than in previously reported cases, and very few cases (approximately 10\%) showed testosterone levels returning to above castration level during follow-up (mean, 25.5 months). These results suggest the possibility of delaying recovery of testosterone levels with long-term hormone therapy. However, no difference in duration of treatment was apparent between those patients in whom testosterone level returned to above castration level and those in whom no such recovery was recognized. Some reports have stated that the duration of hormone therapy is unrelated to the speed of testosterone recovery after discontinuation of hormone therapy (11). This issue requires clarification in future studies.

In addition, some reports have suggested that recovery is delayed in proportion to the age during the period of testosterone recovery after hormone therapy $(10,12)$. Mean age at discontinuation of hormone therapy was 73 years (range, 71-76) in patients with testosterone recovery and 80 years (range, 6790 ) in patients without testosterone recovery, and many patients without testosterone recovery were of advanced age. However, the small number of cases showing testosterone recovery meant that adequate statistical evaluations could not be performed in this study. When predicting factors of testosterone recovery are specified by further study, appropriateness for the adaptation of discontinued, or intermittent hormone therapy for aged people may be made clear.

In conclusion, among 31 patients with non-metastatic prostate cancer and PSA maintained less than $0.5 \mathrm{ng} / \mathrm{ml}$ after $\geqq 5$ years of hormone therapy, we discontinued hormone therapy, then confirmed and examined the presence of PSA relapse and changes in testosterone level. During follow-up (mean, 25.5 months), the PSA non-relapse rate was quite high (87.1\%). These results suggest that many prostate cancer patients receiving treatment may be safely discontinued. In addition, the present findings suggest that a factor exerting major influence on PSA relapse was the speed of testosterone recovery after discontinuation of the treatment, not the radical cure of prostate cancer by long-term hormone therapy. Judgments on when to discontinue hormone therapy may be possible in the future if factors can be identified predicting the rate of testosterone recovery after discontinuation of long-term hormone therapy.

\section{REFERENCES}

1. Cooperberg MR, Grossfeld GD, Lubeck GD, Carroll PR : National practice patterns and time trends in androgen ablation for localized prostate cancer. J Natl Cancer Inst 95 : 981-989, 2003

2. Labrie F, Candas B, Gomez JL, Cusan L : Can combined androgen blockade provide longterm control or possible cure of localized prostate cancer? Urology $60: 115-119,2002$

3. Huggins $\mathrm{C}$, Hodges $\mathrm{CV}$ : Studies on prostatic cancer. I. The effect of castration, of estrogen, and of androgen injection on serum phosphatases in metastatic carcinoma of the prostate. Cancer Res $1: 293-297,1941$

4. Akaza H, Homma Y, Usami M, Hirano Y, Okada K, Yokoyama M, Ohashi Y, Aso Y: Prostate Cancer Study Group : Efficacy of primary hormone therapy for localized or locally advanced prostate cancer : results of a 10-year follow-up. BJU Int 98 : 573-579, 2006

5. Ueno S, Namiki M, Fukagai T, Ehara H, Usami $\mathrm{M}$, Akaza $\mathrm{H}$ : Efficacy of primary hormonal therapy for patients with localized and locally advanced prostate cancer : a retrospective multicenter study. Int J Urol 13 : 1494-1500, 2006

6. Namiki M, Ueno S, Egawa M, Kitagawa Y, Mizobuchi A : Possibility of long-term control or complete cure by hormonal therapy for localized prostate cancer. Hinyoukigeka 18 : 1307 1313, 2005

7. Wilke DR, Parker C, Andonowski A, Tsuji D, Catton C, Gospodarowicz M, Warde P : Testosterone and erectile function recover after radiotherapy and long-term androgen deprivation with luteinizing hormone-releasing hormone 
agonists. BJU Int 97 : 963-968, 2006

8. Kaku H, Saika T, Tsushima T, Ebara S, Senoh T, Tamato T, Nasu Y, Kumon H : Time course of serum testosterone and luteinizing hormone levels after cessation of long-term luteinizingreleasing hormone agonist treatment in patients with prostate cancer. The Prostate $66: 430$ 444, 2006

9. Nejat RJ, Rashid HH, Bagiella E, Katz AE, Benson $\mathrm{MC}$ : A prospective analysis of time to normalization of serum testosterone after withdrawal of androgen deprivation therapy. J Urol 164 : 1891-1894, 2000

10. Oefelein MG : Serum testosterone-based luteinizing hormone-releasing hormone agonist redosing schedule for chronic androgen ablation. Urology 54 : 694-699, 1999

11. Pickles T, Agranovich A, Berthelet E, Duncan GG, Keyes M, Kwan W, Mckenzie MR, Morris WJ : British Columbia Cancer Agency, Prostate Cohort Outcomes Initiative. Testosterone recovery following prolonged adjuvant androgen ablation for prostate carcinoma. Cancer $94: 362$ 367, 2002

12. Pickles T, Graham P : Members of the British Columbia Cancer Agency Prostate Cohort Outcomes Initiative, What happens to testosterone after prostate radiation monotherapy and does it matter? J Urol $167: 2448-2452,2002$ 